he saved Joan from capture. For this, at 25 , he was accorded the unparalleled military honour for his age of being made Marshal of France. When later, in consequence of the king's half-hearted support, Joan of Arc was finally taken, Gilles de Rais set forth again and laid siege to Rouen. Indeed, Joan's martyrdom was probably the turning-point of his life. Leaving the army and court in disgust, Gilles de Rais and a boon companion embarked on a career of seduction and cruel murder of boys. The children were taken to his castle in Normandy, where they were killed slowly by slitting their abdomens or by strangulation during sexual orgies; others were sacrificed for the purposes of black magic. More than 200 such murders were committed before Gilles de Rais was arrested and hanged in 1440 Gilles de Rais, it was said, was the original of the Normandy legend of Bluebeard.

\section{Sadism To-day}

If it were thought, said Dr. Douthwaite in conclusion, that such horrors could not occur in our time, it might be well to ponder what had already taken place in this century. States or dictators had emulated and surpassed Gilles de Rais - and certainly de Sade-in mass murders and torture. One could only pray that our country would never fall into the control of the human fiends who clearly lurked in all societies in every century.

\section{Correspondence}

Because of heavy pressure on our space, correspondents are asked to keep their letters short.

\section{The Black Sheep}

SiR,-Your leading article on this subject (Journal, January 26, p. 217) is timely, on the eve of the month when we expect the peak incidence of Sonne dysentery. During the past three weeks 60 specimens of faeces have been delivered by my patients to our public health laboratory: 11 specimens have been reported positive for Shigella sonnei, 37 specimens were negative from convalescents or contacts of Sonne dysentery, and another 12 negative specimens were from single cases of diarrhoea of a more dramatic type than that associated with Sonne infection. In no case was a patient seriously ill or even confined to bed. Out of seven families (one or more of whose members submitted infected faeces for examination during the past three weeks), four families have good standards of hygiene. One family has no conception of the need for hygiene, and lives in filth. One family is numerous, poorly disciplined, but usually washed. The other family has been dealing with relapses since November (in my opinion through special difficulties beyond their control), but is now finally clear. It is noticeable that quite moderate standards of hygiene suffice to prevent cross-infection, under mother's supervision, but school teachers cannot be expected to enforce successfully proper standards in a crowd if children with diarrhoea are allowed to mix with healthy children in school premises.

Comment on three weeks' results from a single practice can be at best one scene from a moving battle, but it raises the question of whether Sonne dysentery deserves to be dignified by the ritual of notification. It is usually one of the mildest of diarrhoeas, and its very mildness produces the frequent comment from my patients that they know scores of people who continue to send their children to school with diarrhoea. Diarrhoea of any sort should (in a civilized community) be regarded as the result of a breakdown of hygiene and the evacuation of the poison which has been ingested. The sufferer should be isolated, and hand-washing ritual (including soap) be rigorously enforced. I maintain that persistent repetition of this simple theme, through every possible medium of publicity, will do far more to eliminate Sonne dysentery in 1957 than all the painstaking (and heartbreaking) work of laboratories and inspectors in 1956. May I suggest that Sonne has its peak incidence in February just because hand-washing is least welcome in cold weather?I am, etc.,

Nottingham.

Maurice Hargreaves.

\section{Mitral Valve Mobility}

SIR,-I was delighted to see that the view expressed by Professor D. M. Douglas (Journal, January 26, p. 191) on the signs of mobility of the mitral valve coincided so closely with mine. ${ }^{1}$ The "closing" and "opening" snaps are signs of mobility of a diaphragmatic valve, not of stenosis; it so happens that the pathological processes which cause loss of mobility-i.e., heavy scarring or calcification-also lead to regurgitation, as there is no redundant tissue to overlap the rigid vagal orifice during ventricular systole. It is for this reason only that the loud first sound and the "opening snap" have been regarded as signs of pure stenosis. Valve mobility and dominant incompetence may in fact occur together.

I agree with his statement that mitral incompetence may be due to disproportionate shortening of the chordae tendineae in some cases, such as his first and third patients. These clearly had an element of stenosis and were examples of dominant mitral incompetence with diaphragmatic valves: the valve orifice in both was $2 \mathrm{~cm}$. across only. The second case he described was a straightforward example of dominant stenosis with unimportant incompetence also in a diaphragmatic valve. None of the three cases correspond to the group of " hypermobile" valves described. These patients have no stenosis whatsoever; the orifice is at least $4 \mathrm{~cm}$. long. They constitute a different pathological entity, due, I still think, to a rupture of a chorda. I referred to nine cases similar to Professor Douglas's cases 1 and 3. In these I advocated completion of the separation of the cusps despite the presence of dominant mitral incompetence. It is not clear whether or not this was done in his patients. I also referred to 17 valves similar to the one he met in case 2 . As in his case, the results proved fairly good because the stenosis was the main cause of the disability.- I am, etc.,

London, E.2.

J. R. BeLChER.

REFERENCE

1 Belcher, J. R., Lancet, 1956, 2, 7.

\section{Carbon Monoxide Poisoning}

SIR,-The Registrar-General's Statistical Review of England and Wales for the Year 1955, just published, shows that in the three years 1953-5 9,143 persons died of carbon monoxide poisoning-2,168 accidents and 6.975 suicides. This total is 2,000 more than might have been expected from the figures prevailing in the previous five years. A year ago (Journal, February 11, 1956, p. 347) I suggested that increased deaths might possibly have been due to withdrawal from ambulance and other first-aid services of $7 \% \mathrm{CO}_{2}$ and $93 \%$ oxygen on the advice of a committee of the Medical Research Council. The chance of survival of badly poisoned patients depends mainly on the effectiveness of first-aid treatment.

The Medical Research Council asked its statistical research director, Professor A. Bradford Hill, to make an inquiry. His report (Journal, November 24, 1956 p. 1220) concludes that change in resuscitation procedures was not the cause of the large rise in deaths and that this was associated with a concurrent rise in the number of cases occurring as measured by ambulance emergency calls. This conclusion is of great importance because on it may depend official policy in regard to the emergency treatment of a condition which causes nine deaths a day. If it happens to be mistaken then needless loss of life may continue. I submit, with respect, that the evidence upon which it is based is inadequate, and therefore the conclusion may be incorrect. 
The evidence for increase in total cases is presented in three tables. Table II shows London ambulance calls for coal-gas suicidal cases, and the main inference from it reads that "the number of cases carried has, in fact, increased very substantially - from, roughly, a little over 100 in 1951 to 1952 , to well over 200 in 1953 to 1955 ." This inference means that from 1953 onwards coal-gas suicidal attempts in London suddenly doubled. Can this really have happened ? The answer lies in a fallacy, mentioned in the report, concerning change of labelling of cases as "accident" or "suicide." Up till 1952 in London a call was entered as "accident" unless definitely known to be suicide; after 1952 this charitable convention was discontinued and a case was entered as "suicide" unless it was definitely known to to be an accident. Because of this source of error a special search of ambulance records was made for the years 1951 and 1953 and all coal-gas cases extracted irrespective of labels. This showed a rise in total coal-gas emergency calls of $36 \%$ as between these two years. This figure is more credible, but it is a statistical comparison limited only to two selected years. In spite of the admitted labelling flaw, with its probable very large error, table II was still put forward as evidence and the above-quoted inference made that cases increased by $100 \%$.

Tables III and IV show figures from eight provincial towns in which cases increased by $30 \%$. The combined total populations of the eight towns is slightly less than $4 \%$ of the population of England and Wales. What guarantee is there that other towns, from the remaining $96 \%$, might not show different figures? Yet these scanty data, plus fallacious table II, are made the basis for a dogmatic conclusion that cases throughout the country suddenly greatly increased from 1953 onwards.

Whatever else emerges, it is clear that change of first-aid treatment was not followed by any fall in deaths as might have been expected if the theoretical argument in the committee's report had been correct. If there has been no decrease in mortality and, instead, a very big rise in deaths, then why persist with reversion to treatment discarded over a quarter of a century ago ? Why not at least try $\mathrm{CO}_{2} / \mathrm{O}_{2}$ once more (for carbon monoxide poisoning only) and see if deaths fall ? Over a year ago (Journal, October 15, 1955 , p. 966) the chairman of the committee said experimental work was planned. It would seem time that the implication of this work should be apparent. If it is not unequivocally in favour of pure oxygen then it is surely indefensible to continue to deny $\mathrm{CO}_{2} / \mathrm{O}_{2}$ to first-aid services.

It now becomes evident that the advice of the committee was circulated to local authorities about four years before publication in the medical press. This may have been done in response to requests for guidance, but such practice may be dangerous-particularly when unproved advice, contrary to accepted opinion, is put out under the prestige label of the Medical Research Council. Administrative officials, medical or lay, can hardly fail to act on it. Publication in medical journals is less mandatory because officials do not receive it in the guise of circulated instruction from higher authority. And publication has the vital safeguard that public criticism can be made in time if there is chance of error. It is disquieting that a small committee can scrap a standard method of treatment, for a common and urgent condition, without the medical profession as a whole being informed till years afterwards.

The most serious consequence of private direction, long prior to publication, is that the Medical Research Council may be put in an awkward position if there is subsequent question that the advice given may have been wrong and caused loss of life. The council is then on the defensive, and in consequence its ability to weigh the matter dispassionately becomes open to doubt. Because that is the present situation, I submit, Sir, that there are grounds for Ministerial or Parliamentary inquiry concerning the desirability of transfer of official advisory responsibility regarding carbon monoxide poisoning to some other body.-I am, etc.,

London. W.1.

H. L. MARRIott.

\section{Vaccination Against Whooping-cough}

SIR,-In a reprint of the report to the Medical Research Council on vaccination against whooping-cough (Journal, August 25, 1956, p. 454) I read the following opinion : "Thus the use of chloramphenicol for the siblings of vaccinated children did not reduce the risks of the vaccinated children developing the disease." At the Clinic for Infectious Diseases in Childhood, Warsaw, we think this conclusion is in some respects not quite correct, as it does not take into consideration the time at which chloramphenicol is given. It is possible that if given too late it will not be effective in preventing the disease.

I would like to report our results with chloramphenicol administered for a longer period to protect children exposed to the risk of developing whooping-cough. We started our trials on the supposition that, although vaccination is the main prophylactic measure against pertussis, it has its deficiencies. First, the degree of immunity acquired from vaccination is uncertain, and, secondly, vaccination of newborn infants, so far as I can gather from the literature accessible to me, has not as yet given any clear results. Yet up to the age of 6 months the mortality from pertussis is high.

With this in mind we carried out trials in the home, where there were infants in contact with older children who had contracted the disease, and in nursery schools for babies up to 3 years. There were 271 children in four schools. At the time of the trial there were 37 cases of pertussis (tested bacteriologically, clinically, and by blood examination). As soon as they were diagnosed the sick children were sent home or to hospital, but in spite of this further cases developed. We therefore started the administration of chloramphenicol prophylactically. Some of the children had been vaccinated, and we had also had cases of pertussis among vaccinated children earlier on.

Chloramphenicol was given in doses of $50 \mathrm{mg} . / \mathrm{kg}$. body weight every 24 hours for 7 to 10 days under blood examination control and urinanalyses. Chloramphenicol was given four times a day-three times in the nursery school and once at home. Bacteriological examinations were carried out after the treatment was finished. The pertussis bacillus was not once found in those children. After this prophylactic treatment was started not one child developed whooping-cough, and after three weeks new children were admitted to the schools without any further cases developing. In 20 home exposure cases chloramphenicol failed to prevent the onset of the disease only in one case. Therefore it seems that the administration of chloramphenicol for 7 to 10 days has a strong sterilizing action on the whooping-cough bacilli, and that it is worth while trying this method against the infection, especially in infancy. We have no experience in prophylaxis with hyperimmune serum or gamma-globulin. This method is very troublesome, and there are difficulties in obtaining these substances in quantities sufficient for large-scale trials.-I am, etc.,

Warsaw.

J. BOGDANOWICZ.

\section{Rh-Hr Nomenclature}

SIR,-The purpose of this letter is to call the attention of your readers to the tentative supplementary report of the committee on Medico-Legal Problems of the American Medical Association on the Medico-Legal Application of Blood Grouping Tests. ${ }^{1}$ The most important item in this report is the recommendation of a single uniform system of $\mathrm{Rh}-\mathrm{Hr}$ nomenclature for medico-legal reports. "It is recommended that unless and until some other convention can be agreed upon the original $\mathrm{Rh}-\mathrm{Hr}$ notations must be retained as the standard and sole nomenclature for the preparation of approved medico-legal reports on $\mathrm{Rh}$ types." In response to an editorial request for criticisms and suggestions, close on 50 letters were received from workers in the field. Approximately half the correspondents heartily approved the recommendation, whereas the remainder vigorously attacked it. The adverse criticisms have been 